$23^{\text {rd }}$ Congress of the International Union for Biochemistry and Molecular Biology

$44^{\text {th }}$ Annual Meeting of the Brazilian Society for Biochemistry and Molecular Biology

Foz do Iguaçu, PR, Brazil, August $24^{\text {th }}$ to $28^{\text {th }}, 2015$

\title{
LEARNING AS A TOOL FOR CANCER PREVENTION THROUGH THE ACQUISITION OF NEW DIETARY HABITS AND BEHAVIORS
}

\author{
BRITO, Juliane Ferreira de ${ }^{1}$; DALLA SANTA, Herta Stutz ${ }^{2}, \underline{\text { REBECA, }^{2} \text { Rosilene }^{3}}$
}

${ }^{1}$ Acadêmica do curso de Ciências Biológicas, Universidade Estadual do Centro- Oeste (UNICENTRO), Paraná, Brasil.

\footnotetext{
2 Professora Adjunta do Departamento de Engenharia de Alimentos, Universidade Estadual do Centro-Oeste (UNICENTRO), Paraná, Brasil.
}

${ }^{3}$ Professora Adjunta do Departamento de Ciências Biológicas, Universidade Estadual do CentroOeste (UNICENTRO), Paraná, Brasil.

The need to promote knowledge of health entails, in part, by encouraging healthy eating habits. The creation of popular science materials, especially at schools, by promoting guidance for the eating habits is presented as an important tool. Foods that contain bioactive compounds are called nutraceutical foods and about $35 \%$ of various cancers occur due to inadequate diets. Conventional therapies are used in the treatment of cancer, even though they are efficient in fighting tumors, to cause many harmful effects to the patient, and therefore the researches for alternative therapies have increased. Especially those act strengthening the immunologic system. The mushrooms are able to modulate carcinogenesis in all stages of the disease through different mechanisms of action of the bioactive compounds, thus having an antitumor effect that is assigned to restore and improve the immune response through stimulation of cellular immunity which are present polysaccharides the composition of the mushrooms, such as betaglucans that besides the anticancer effect, it still has activity as immunostimulant, antioxidant, anti-inflammatory, which are already used in Japan as drugs for treating cancer patients. The aim of this work was to use learning as a tool for acquiring habits and eating behaviors in the general community and ownership and acquisition of knowledge about the antitumor potential of bioactive compounds in foods which are applied in cancer prevention through the scientific dissemination / education. Because it is a popular science work using written material and the dissemination of the material make for yourself the methodology used for the dissemination of scientific knowledge. Thus, the inclusion of consumption of mushrooms in the diet may represent an important step in the cancer prevention as the best form of prevention, and therefore it shows the need for available information to everyone, as it has proposed this work, disclosure.

Keywords: Learning. Cancer prevention. Bioactive compounds. 